\title{
Development of Profitable Phytoremediation of Contaminated Soils with Biofuel Crops
}

\author{
Kokyo $\mathrm{Oh}^{{ }^{*}}$, Tao $\mathrm{Li}^{2}$, Hongyan Cheng ${ }^{2}$, Xuefeng $\mathrm{Hu}^{3}$, Chiquan $\mathrm{He}^{3}$, Lijun $\mathrm{Yan}^{3}$, Yonemochi Shinichi ${ }^{1}$ \\ ${ }^{1}$ Center for Environmental Science in Saitama, Saitama, Japan; ${ }^{2}$ College of Resources and Environment, Shanxi University, Taiyuan, \\ China; ${ }^{3}$ School of Environmental and Chemical Engineering, Shanghai University, Shanghai, China. \\ Email: ${ }^{*}$ o.kokyo@pref.saitama.lg.jp
}

Received February $15^{\text {th }}, 2013$; revised March $18^{\text {th }}, 2013$; accepted April $16^{\text {th }}, 2013$

Copyright (C) 2013 Kokyo Oh et al. This is an open access article distributed under the Creative Commons Attribution License, which permits unrestricted use, distribution, and reproduction in any medium, provided the original work is properly cited.

\begin{abstract}
Contamination of agricultural soil has been a worldwide concern, and phytoremediation is a promising alternative to conventional soil clean-up technology as a low cost and environment-friendly technology. However, the field application of phytoremediation is still limited, because of its low efficiency and long-period needed. In this paper, with discussion of the characteristics, mechanisms and development of phytoremediation, we suggested a profitable phytoremediation strategy using biofuel crops for both utilization and remediation of contaminated soil. In this strategy, the owners of contaminated sites possibly cost nothing, but obtain income through selling the biofuel crop for factories produced biofuel, thus the practical application of phytoremediation can be effectively promoted. In order to test the feasibility of the suggested strategy, a hydroponic cultural experiment and a pot experiment were carried out to assess the phytoremediation potential of some biofuel crops. The hydroponic cultural experiment showed that the two biofuel plants, sunflower and maize, had a better or similar accumulation level of $\mathrm{Pb}, \mathrm{Cu}$ and $\mathrm{Cd}$ than the two accumulator plants. The pot cultural experiment showed that wheat and barley with white-rot-fungus inoculation greatly promoted crop biomass, soil microbial population, and dioxins removal efficiency. These results indicate that phytoremediation using biofuel plants possibly works effectively for remediation of contaminated soils as well as provide economic benefits to the owners of contaminated sites. Therefore, biofuel crops would be a reasonable choice for phytoremediation of contaminated soils.
\end{abstract}

Keywords: Contaminated Soil; Heavy Metals; Organic Contaminants; Phytoremediation; Biofuel Plants

\section{Introduction}

Soil is the foundation of terrestrial ecosystems and a nonrenewable fundamental agricultural resource, inextricably linked to productivity, land development and environmental quality [1]. However, extensive soil contamination with hazardous pollutants including inorganic and organic pollutants (i.e. $\mathrm{Cd}, \mathrm{Pb}, \mathrm{Cu}, \mathrm{Hg}$, As, pesticides, dioxins) has been a worldwide concern over the last decades, especially in Asian countries, where urbanization and industrialization are rapidly forwarding. For example, there are many cases of heavy metal contamination originating from old mines and smelters in Japan and China. In particularly, the radiation released by the crippled $\mathrm{Fu}-$ kushima (Japan) nuclear power plant in March 2011 caused extensive soil contamination. In China, it is well known that more than $10 \%$ of the arable land has been

\footnotetext{
*Corresponding author.
}

contaminated [2]. These extensive contaminated soils are posing great risks to crop production, human health and the regional environment. Therefore, there is a great need to remediate these contaminated soils with suitable methods.

Although there are some physicochemical soil remediation engineering techniques such as soil washing, incineration, solidification, thermal desorption, and disposal as waste, however, these method are usually need extremely high cost, destroy the properties of soils, and cause secondary air or water pollution, so it is not suitable for remediation of agricultural soils $[3,4]$.

In the past several decades, phytoremediation, the use of green plants and their associated microbiota for the in situ treatment of soil, sediment, water and air, has received increasing attention as a cost-effective and ecofriendly technology for remediation of contaminated soils [46]. By growing plants in the contaminated sites, conta- 
minants in soils will be removed, immobilized, or degraded, and the cost is much less expensive than other traditional methods $[5,7]$.

The conventional phytoremediation method has focused on special plants such as metal hyper accumulator or accumulator plants, which is capable of accumulating potentially phytotoxic elements to concentrations much higher than the normal plants growing in the same environment $[8,9]$. However, most of these accumulator plants usually had very high heavy metal contents, so after harvested the plants usually need incineration treatment [10]. In this way, the conventional phytoremediation needs cost year by year, and the owners of the contaminated sites have no income during the remediation period, which has been limited the practical application of phytoremediation $[11,12]$.

In recent years, biofuel crops and other economic plants are receiving increasingly attention as they can both remediate contaminated soils, and produce valuable biomass, through which the practical application of phytoremediation can be promoted and the soil resources can be protected $[12,13]$.

The objectives of this paper are to discuss the development of phytoremediation, its efficiency enhancing methods, and to suggest a profitable application systems with biofuel crops for promotion to the practical application of phytoremediation.

\section{Soil Phytoremediation and Its Development}

Soil phytoremediation is a technology using plants and their associated rhizospheric microorganisms to remove various pollutants from contaminated soils $[5,8,14]$. Phytoremediation of contaminated soils is generally believed to be effective through one or more of the following mechanisms or processes: phytoextraction, phytostabilization, phytodegradation, phytovolatilization, and rhizodegradation $[5,8,15]$. These mechanisms are described briefly in Table 1.

With application of phytoremediation in the management and remediation of contaminated soils, the main positive characteristics includes: 1) it is in situ remediation and the energy is supplied by solar, so the costs are very low in comparison to other physiochemical methods, and 2) it can remove pollutants from soil and reduce their movement towards groundwater, sustains the soil properties, and enhance soil quality and productivity, and thus can prevent the loss of soil resources. However, as a plant-based technology, phytoremediation has its main limitations as follows: 1) its remediation rate is low, and thus generally a longer period (usually over 3 or 5 years) is needed comparing to other physicochemical methods, 2) the remediation rate is easily influenced by the climate,
Table 1. Phytoremediation mechanisms for treatment of contaminated soils.

\begin{tabular}{|c|c|}
\hline Mechanisms & Description \\
\hline Phytoextraction & $\begin{array}{l}\text { Plants absorb contaminants and store in } \\
\text { above-ground shoots and the harvestable } \\
\text { parts of roots. }\end{array}$ \\
\hline Phytostabilization & $\begin{array}{l}\text { Roots and their exudates immobilize } \\
\text { contaminants through adsorption, } \\
\text { accumulation, precipitation within the } \\
\text { root zone, and thus prevent the spreading } \\
\text { of contaminants. }\end{array}$ \\
\hline Phytodegradation & $\begin{array}{l}\text { Plant enzymatic breakdown of organic } \\
\text { contaminants, both internally and through } \\
\text { secreted enzymes. }\end{array}$ \\
\hline $\begin{array}{l}\text { Rhizodegradation } \\
\text { (phytostimulation) }\end{array}$ & $\begin{array}{l}\text { Plant roots stimulate soil microbial communities } \\
\text { in plant root zones to break down contaminants. }\end{array}$ \\
\hline Phytovolatilization & $\begin{array}{l}\text { Contaminants taken up by the roots through } \\
\text { the plants to the leaves and are volatized } \\
\text { through stomata where gas exchange occurs. }\end{array}$ \\
\hline
\end{tabular}

soil conditions and management practices. According to these characteristics, phytoremediation are more suitable for remediation of contaminated sites with a large area but a low contamination level.

Phytoremediation is still an emerging field. The systematic study on phytoremediation for heavy metal contaminated soils is from 1980s, and that for organic contaminants is more recent $[4,7,8]$. Anyway, much progress has been made in phytoremediation of various contaminants, and in the means for enhanced phytoremediation.

Phytoremediation to date indicates that it is applicable to a wide range of inorganic pollutants (such as $\mathrm{Cd}, \mathrm{Cr}$, $\mathrm{Pb}, \mathrm{Cu}, \mathrm{Zn}, \mathrm{Co}, \mathrm{Ni}, \mathrm{Se}, \mathrm{Hg}$, Cs and $\mathrm{As}$ ) and organic pollutants (such as petroleum hydrocarbons, pesticides, chlorinated solvents, dioxins, and surfactants) $[4,5]$.

So far, phytoremediation of various inorganic pollutants is mainly based on the use of natural hyperaccumulator plants with exceptional metal-accumulating capacity, which can take up metals to concentrations at least an order of magnitude greater than the normal plants growing in the same environment $[4,16]$. At present, there are totally more than 400 species of hyperaccumulator plants have been found, for instance, accumulation concentration of Thlaspi caerulescens is $51,600 \mathrm{mg} / \mathrm{kg}$ for $\mathrm{Zn}$ and $18,000 \mathrm{mg} / \mathrm{kg}$ for $\mathrm{Cd}$, Ipomea alpine is $12,300 \mathrm{mg} / \mathrm{kg}$ for $\mathrm{Cu}$, and Pteris vitatta is $20,000 \mathrm{mg} / \mathrm{kg}$ for As $[4,17]$.

Many plant species, which is effective for remediation of organic contaminants, have also been screened out. For instance, Indian mustards, willow, hybrid poplars, duckweed, corn, pumpkin, ryegrass, bean plants, clover, alfalfa, and ryegrass are popularly used $[4,17,18]$.

\section{Studies on Enhanced Phytoremediation}

One of the most limitations for phytoremediation is the 
low remediation effeciency. Therefore, studies on the means for enhancing phytoremdiation have been extensively carried out. The measures for enhanced phytoremediation mainly include the following ways.

\subsection{Chemically Enhanced Phytoextraction}

This approach is to increases mobility of metals in soil by chemical treatments, so that the metals can be taken up more easily by plants [6]. Several chelating agents or surfactants, such as citric acid, EDTA, CDTA, DTPA, EGTA, EDDHA, and NTA, has been studied and used to mobilize metals and increase metal accumulation in plant species $[6,14]$. However, some concerns have been expressed regarding the enhanced mobility of metals in soil and their potential risk of leaching to groundwater. Moreover, these soil amendments may also persist in the environment creating additional and unforeseen problems [14].

\subsection{Genetically Engineered Plants}

Genetically altering the high biomass plants to extract larger amounts of metal from soils, or improving the biomass production of some hyperaccumulator plants, molecular cloning and expression of heavy metal accumulator genes and xenobiotic degrading enzyme coding genes would resulted in enhanced phytoremediation rates [14]. This technology could be a promising approach in the future, although so far no genetically engineered plants have been used commercially in phytoremediation, because of the reasons including the various safety aspects and regulatory limitation for outdoor use of such plants [4].

\subsection{Routine Agricultural Techniques}

For instance, suitable fertilization and carbon source addition can promote plant growth and microbial activities, and then can greatly enhance phytoremediation. Huang et al. [19] used a multi-process phytoremediation for enhancing the clean-up of the persistent organic contaminants from soil. This system includes land farming (aeration and light exposure), microbial inoculation (introduction of contaminant degrading bacteria), and phytoremediation (plant growth). The system effectively increases the remediation rate, and possibly shorten more than $50 \%$ of the remediation period compared with phytoremediation only.

\subsection{Developing Plant-Microbe Systems}

The rhizosphere may be inoculated with a new strain of microorganism that is more effective in degrading the contaminant than the local microflora. In some plant-microbe systems, the plant growth can promote the activity and growth of the effective microbes, and the growth of microbes can also promote the plant growth, thus enhancing the efficiency of phytoremediation. Mycorrhizae is also used for enhancing phytoremediation. Inoculation of mycorrhizae to some plants may promote the uptake, translocation and accumulation of soil metals $[16,17,20]$.

Researches by our research group recently focus on establishing profitable and efficient phytoremediation systems. We use combination systems of biofuel crops such as barley, wheat and corn with white rot fungi for remediation of soil organic contaminants. Results showed that microbial activities, plant growth as well as the remediation efficiency of dioxins were promoted [8]. Although crops growing in the contaminated soil cannot be eaten as food, they can be used for production of biofuels. Therefore, the biofuel crop based phytoremediation can bring income for the owner of the contaminated sites. Thus, the owner possibly cost nothing but on the contrary can obtain the same profit as the general farm land every year during the phytoremediation period. In this way, the practical application of phytoremediation could be greatly promoted, because one of the key factors limited the practical application of phytoremediation is that phytoremediation needs cost year by year within the remediation period. Although cost of phytoremediation is much lower than other methods, but phytoremediation makes the owner of the contaminated sites no income during the long period of remediation, which greatly limit its practical application.

\section{The Strategy of Profitable Phytoremediation with Biofuel Crops}

Phytoremediation has been extensively studied for more than thirty years, and many companies have started their business in phytoremediation. However, its practical application is still few, despite the firm establishment of phytoremediation technologies in the literature and in smallscale demonstrations $[12,21]$. There have been some project applications in America, Canada and other countries with field-scales since the 1980s. Anyway, only limited information is available about project performance and time frames for project completion [22].

One of the key factors limited the practical application of phytoremediation is its "cost". In the conventional phytoremediation, special plants for phytoremediation are mainly used so far, such as the hyperaccumulator plants. After harvested, the plants are treated with incineration because of their high metal accumulation. The individual plants of these special plants are usually small, slow growing, and lack of economic value $[4,13]$. Moreover, most of the hyperaccumulator plants are comercially protected with patents, so their seeds or seedlings are expensive. Therefore, the conventional phytoremediation 
needs cost year by year, making the owners of the contaminated sites no income during the remediation period, thus, greatly limits its practical application (Figure 1). In order to overcome this problem, in recent years, we focused on establishing profitable phyotoremediation systems by using biofuel plants (i.e. Maize, sunflower, soybean, barley and wheat) $[3,12]$, as we think that the agricultural contaminated soils should be regarded as recoverable resources, not waste substances, for both utilization and remediation. As shown in Figure 1, in the profitable phytoremediation system, instead of the special plants for phytoremediation (i.e hyperaccumulator plants), the biofuel crops was used. Biofuel crops in the contaminated soil will not be used as food for people, but use for biofuel production through sale to biofuel factories. Therefore, the biofuel crops can bring income for the owner of the contaminated sites by selling them to the factories produced biofuel. In this way, the owners cost nothing, and on the contrary, they can obtain income from the contaminated land every year during the phytoremediation period. Thus, the practical application of phytoremediation can be greatly promoted.

At present, we are in the early stages of testing the strategy and several experiments have been carried out, and the brief introduction is as follows.

\subsection{Heavy Metal Accumulation Potential of Biofuel Plants-Hydroponic Experiment}

\subsubsection{Materials and Methods}

The hydroponic culture was used in this study. Two biofuel crops, maize (Zea mays L.) and sunflower (Helianthus annuus L.), and two accumulator Elsholtzia spleendens and Kummerowia striata were used. The 3-week seedlings of the plants were transferred to a nutrient solution for five day culture. Control, $0.01 \mathrm{~mol} / \mathrm{L}$ and 0.1 $\mathrm{mol} / \mathrm{L}$ level of $\mathrm{Pb}, \mathrm{Cu}$ and $\mathrm{Cd}$ treatments were applied, added as $\mathrm{Pb}\left(\mathrm{NO}_{3}\right)_{2}, \mathrm{Cu}\left(\mathrm{NO}_{3}\right)_{2} \cdot 3 \mathrm{H}_{2} \mathrm{O}$, and $\mathrm{Cd}\left(\mathrm{NO}_{3}\right)_{2} \cdot 4 \mathrm{H}_{2} \mathrm{O}$, respectively. The plants were grown in the greenhouse, with average temperature of approximately $28^{\circ} \mathrm{C}$ at the day time and $20^{\circ} \mathrm{C}$ at night. The plants were harvested after five days of treatment for assay of $\mathrm{Pb}, \mathrm{Cu}$ and $\mathrm{Cd}$ contents in different part of the plants. The experiment was randomly arranged with three replicates for each treatment. The solution was aerated and maintained at $\mathrm{pH} 5.8$ \pm 0.3 adjusted with $0.1 \mathrm{~mol} / \mathrm{L} \mathrm{NaOH}$ or $0.1 \mathrm{~mol} \cdot \mathrm{L}^{-1} \mathrm{HCl}$, and was renewed every day during the experiment. $\mathrm{Pb}$, $\mathrm{Cu}$ and $\mathrm{Cd}$ of the plants were digested with hot-plate method and analyzed using ICP-AES.

\subsubsection{Results and Discussion}

The heavy metal accumulation in each pot (3 seedlings) of the four plants in the solution with $0.01 \mathrm{~mol} / \mathrm{L}$ of $\mathrm{Pb}$, $\mathrm{Cu}$ and $\mathrm{Cd}$, respectively was shown in Figure 2. Sun flower showed the highest accumulation ability for $\mathrm{Pb}$, $\mathrm{Cu}$ and $\mathrm{Cd}$ in the aboveground part compared to other three plants. Maize showed a similar accumulation level with other two accumulator plants.

The heavy metal concentration in the plants increased with the increase of metal addition levels. As shown in Figure 3. Cd concentration under $0.1 \mathrm{~mol} / \mathrm{L} \mathrm{Cd}$ application in the shoot for maize, ES and KS were 4 - 11 times that under $0.01 \mathrm{~mol} / \mathrm{L}$ treatment. Under the $0.01 \mathrm{~mol} / \mathrm{L}$ $\mathrm{Cd}$ level, the sunflower had the highest $\mathrm{Cd}$ concentration. However, under the $0.1 \mathrm{~mol} \cdot \mathrm{L}^{-1} \mathrm{Cd}$ level, sunflower had the lowest $\mathrm{Cd}$ concentration ( $49 \mathrm{ug} / \mathrm{L}$ ). The reason was that the sunflower seedlings died in the $0.1 \mathrm{~mol} / \mathrm{L} \mathrm{Cd}$ solution. Possibly as the sunflower had a poor tolerance compared to other plants.

Briefly, the results indicated that the two biofuel plants had a better or similar accumulation level of $\mathrm{Pb}, \mathrm{Cu}$ and $\mathrm{Cd}$ than the two accumulator plants. So, biofuel crops are possibly a promising way for utilization and remediation of contaminated soils. As sun flower had a poor tolerance to heavy metals, it is possibly more suitable for soils with a low contamination level.

\subsection{Phytoremediation of Contaminated Soils of Organic Pollutants with Biofuel Crops and Effective Microorganisms}

In order to enhance phytoremediation efficiency of soil organic contaminants, a biofuel crop-microbe combination system was developed, and the effects on plant biomass,

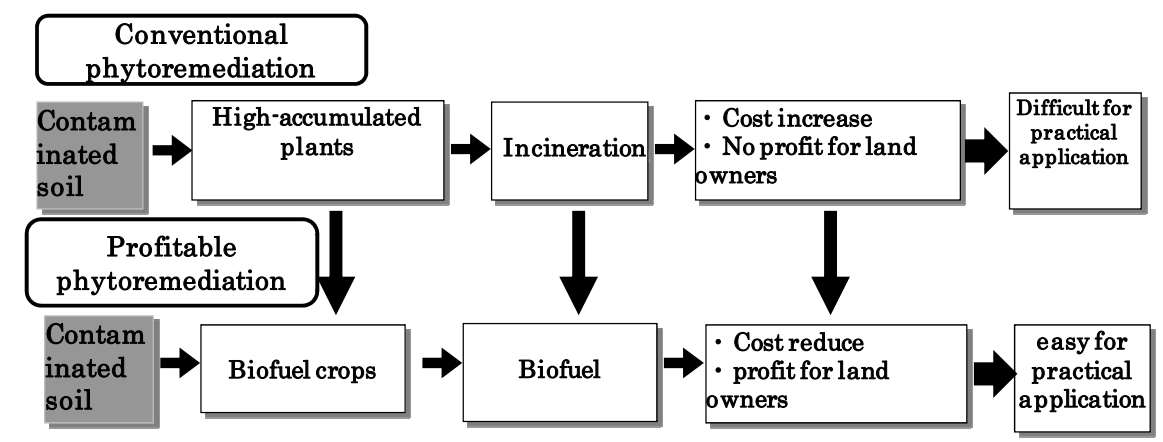

Figure 1. Comparison of conventional phytoremediation and the profitable phytoremediation with biofuel crops. 


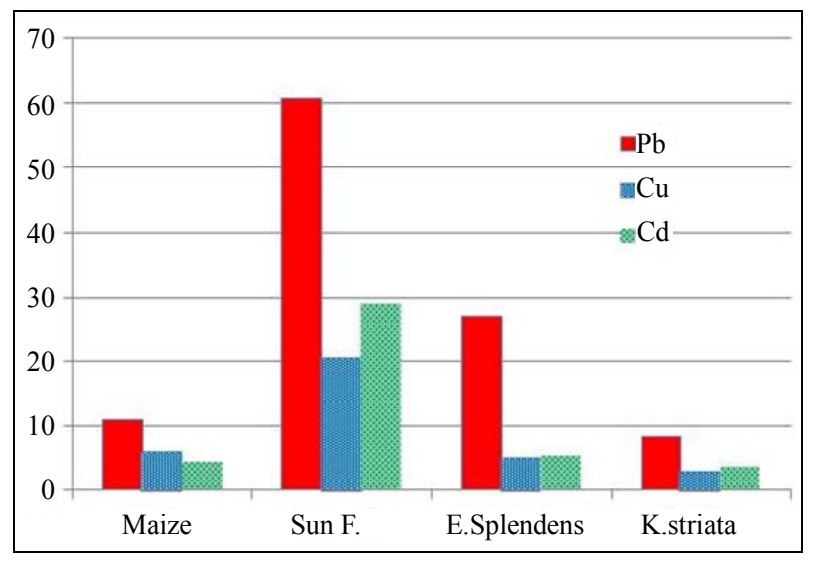

Figure 2. Heavy metal accumulation in the above-ground parts of the plants (ug/pot).

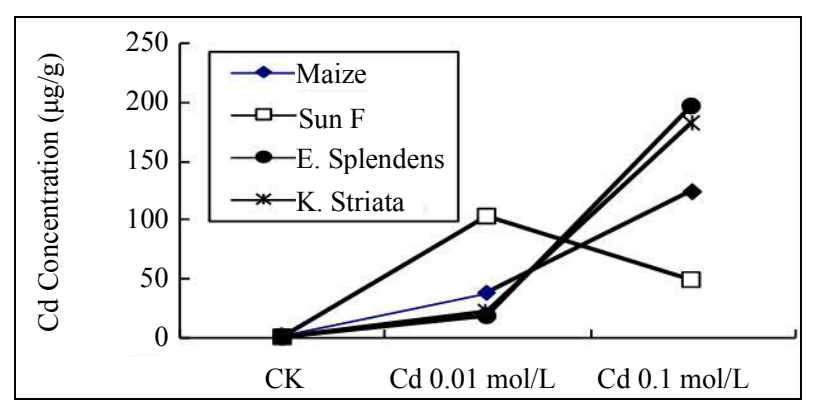

Figure 3. Cd concentrations in plants of above ground part.

soil microbes, and remediation efficiency were assessed.

\subsubsection{Materials and Methods}

Two biofuel crops, wheat (Triticum spp.) and barley (Hordeum vulgare L.), were grown in pots filled with a dioxins-contaminated soil or with a natural arable soil. The microbe used was Hiratake (Pleurotus ostreatus), a white-rot-fungus with high health safety and high degradation potential to organic contaminants. The pots were put in the field of the Center for Environmental Science in Saitama with natural atmospheric condition during November 2007 and June 2008. The crop seedlings were then given the following treatment 30 days after emergence 1) non-inoculation, and 2) inoculation with $\mathrm{Hi}$ ratake, with control treatments of non-vegetated pots. No microbe inoculation made to the natural arable soil. Three replicates of each treatment were removed when harvested for soil and plant analysis.

At the day of crop harvest, three pots in each treatment were randomly removed for soil and crop sampling. The above-ground part of the crops were collected, and dried in a drying oven for measuring the dry biomass. Microbial number of total bacteria and fungi in the soil were measured using the spread plate method. The microbial number was expressed as the number of colony forming units (cfu/g). For dioxin analysis, $10 \mathrm{~g}$ air dried and tho- roughly mixed soil was Soxhlet extracted with toluene for 24 hours. Then, after adding ${ }^{13} \mathrm{C}$-labeled internal standards, the extracts were cleaned up according to procedures published by the Ministry of the Environment of Japan with minor modification. The last fraction was concentrated and spiked with two ${ }^{13} \mathrm{C}$-labeled PCDD/Fs and four ${ }^{13} \mathrm{C}$-labeled co-PCBs internal standards for $\mathrm{HRGC} /$ HRMS analysis

\subsubsection{Results and Discussion}

Increase in the total biomass of the wheat and barley, and their ear yields were found in treatments with Hiratake compared with that without inoculation (Figure 4). However, biomass and ear yields were much lower than that of the natural arable soil. This indicates that the contaminated soil had worse condition for plant growth than arable soil, but Hiratake inoculation can promote crop growth in the contaminated soil.

The number of soil microorganisms also greatly increased in the Hiratake inoculation treatments with crop (data not show), compared with those without crop grown. The promotion of the soil microorganisms is beneficial for enhancing remediation of soils with organic contaminants. For remediation of dioxins, nearly no differences were found in dioxins concentration among the treatment without crop plantation (Figure 5). The treatments with only wheat or barley had slight decrease in dioxins concentration, but wheat or barley plantation with Hiratake inoculation had larger decrease. Compared with the original soil, barley with Hiratake (BM) had a $35 \%$ decrease in soil dioxins, while wheat with Hiratake (WM) had a $24 \%$ decrease (Figure 5).

In summary, wheat and barley with Hiratake inoculation greatly promoted crop biomass and ear yields, soil microbial population, and dioxins removal efficiency. The results indicate that combination of white-rot fungi with suitable biofuel crops was possibly an efficient choice for enhancing remediation of soils contaminated

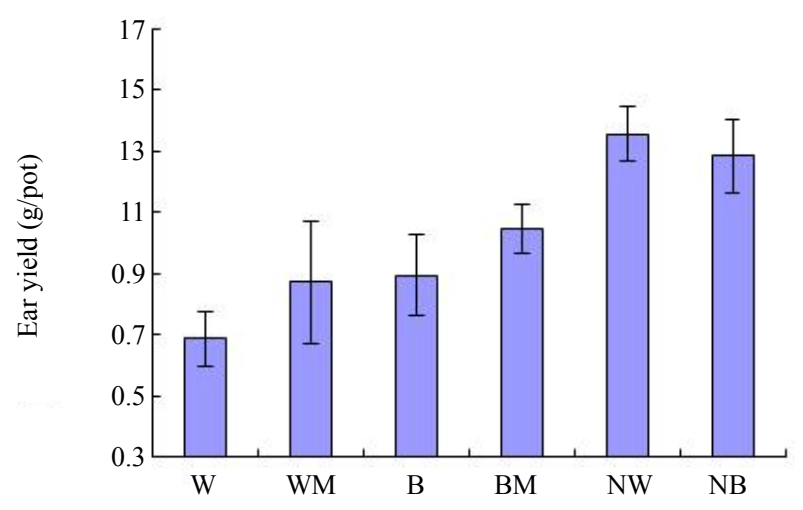

Figure 4. Biomass in treatments with or without Hiratake inoculation (W: Wheat; B: Barley; M: Hiratake; N: Natural arable soil). 


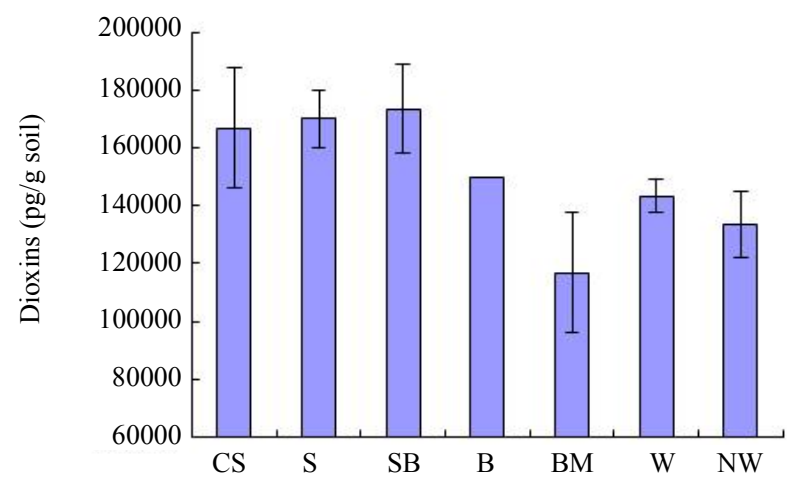

Figure 5. Soil dioxin concentrations after remediation using wheat and barley for six months (OS: Original contaminated soil; S: Contaminated soil only; M: Pleurotus ostreatus; B: Barley; W: Wheat).

with organic pollutants.

\section{Conclusions}

Phytoremediation have long been suggested to remediate contaminated soils as a low cost and environmental friendly technology. At present, more than 400 hundreds of hyperaccumulator plants have been found and various measures have been developed for enhanced phytoremediation. Anyway, as phytoremediation need a long period, the low cost has hindered its practical application.

Instead of the special plants for phytoremediation, biofuel crops were suggested to use for remediation and utilization of contaminated agricultural soils. The primary studies concluded that the two biofuel plants, sun-flower and maize generally had higher or similar phytoremediation potential for heavy metals compared to the two accumulator plants. Moreover, with combination of whoterot-fungus with wheat and barley, crop biomass, soil microbial population, and organic pollutants (dioxins) removal efficiency were greatly promoted.

From this study, we could primarily concluded that the use of biofuel crops for utilization and remediation of the contaminated soils would be a reasonable choice, as they could remediate contaminated soils and produce valuable biomass, which could bring income for the owners of the contaminated sites. Moreover, biofuel crops were easy for management, produced large biomass and had comparable remediation rates to some special phytoremediation plants. Our further study would focus on establishing stable and efficient phytoremediation systems based on biofuel crops through field experiments in different areas.

\section{Acknowledgements}

We are grateful to the partial support of the Grant-in-Aid for Scientific Research of Japan Society for the Promotion of Science (No. 20-08623 and No. 23405049), and the National Natural Science Foundation of China (No. 41130526).

\section{REFERENCES}

[1] W. X. Zhu, "Consideration of Soil Ecological Processes in Restoration and Succession," Phytoecological Sinica, Vol. 29, No. 3, 2005, pp. 479-486.

[2] L. Li, "More than $10 \%$ of Arable Land Polluted," China Daily, 2007.

http://www.cenews.com.cn/xwzx/fz/qt/201012/t20101231 691319.html

[3] K. Oh, S. Hosono, Q. Lin, Y. H. Xie, F. Y. Li, C. J. Jiang and T. Hirano, "Remediation of Dioxin-Contaminated Soil with Combination of Biofuel Crops and White Rot Fungus," Organohalogen Compounds, Vol. 71, 2009, pp. 1177 1182.

[4] X. J. Wang, F. Y. Li, M. Okazaki and M. Sugisaki, "Phytoremediation of Contaminated Soil," Annual Report CESS, Vol. 3, 2003, pp. 114-123.

[5] P. Ji, T. Sun, Y. Song, M. L. Ackland and Y. Liu, "Strategies for Enhancing the Phytoremediation of CadmiumContaminated Agricultural Soils by Solanum nigrum L.," Environmental Pollution, Vol. 159, No. 3, 2011, pp. 762 768. doi:10.1016/j.envpol.2010.11.029

[6] C. A. Salt, R. D. Smith and I. Raskin, "Phytoremediation," Annual Review of Plant Physiology and Plant Molecular Biology, Vol. 49, No. 1, 1998, pp. 643-648. doi:10.1146/annurev.arplant.49.1.643

[7] P. Ahmadpour, F. Ahmadpour, T. M. M. Mahmud, Arifin Abdu, M. Soleimani and F. H. Tayefeh, "Phytoremediation of Heavy Metals: A Green Technology," African Journal of Biotechnology, Vol. 11, No. 76, 2012, pp. 1403614043. doi:10.5897/AJB12.459

[8] K. Oh, S. Hosono, Q. Lin, Y. H. Xie, F. Y. Li, C. J. Jiang and T. Hirano, "Remediation of Dioxin-Contaminated Soil with Combination of Biofuel Crops and White Rot Fungus," Organohalogen Compounds, Vol. 71, 2009, pp. 1177-1182.

[9] I. D. Pulford and C. Watson, "Phytoremediation of Heavy Metal-Contaminated Land by Trees-A Review," Environmental International, Vol. 29, No. 4, 2003, pp. 529540. doi:10.1016/S0160-4120(02)00152-6

[10] K. Oh, T. Li, H. Y. Cheng, X. Hu, Q. Lin and Y. Xie, “A Primary Study on Assessment of Phytoremediation Potential of Biofuel Crops in Heavy Metal Contaminated Soil," Applied Mechanics and Materials, Vol. 295-298, 2013, pp. 1135-1138.

doi:10.4028/www.scientific.net/AMM.295-298.1135

[11] W. Chintakovid, P. Visoottiviseth, S. Khokiattiwong and S. Lauengsuchonkul, "Potential of the Hybrid Marigolds for Arsenic Phytoremediation and Income Generation of Remediators in Ron Phibun District, Thailand," Chemosphere, Vol. 70, No. 8, 2008, pp. 1532-1537. doi:10.1016/j.chemosphere.2007.08.031

[12] R. B. Meagher, "Phytoremediation of Toxic Elemental and Organic Pollutants," Current Opinion Plant Biology, Vol. 3, No. 2, 2000, pp. 153-162. 


$$
\text { doi:10.1016/S1369-5266(99)00054-0 }
$$

[13] B. Robinson, S. Green, T. Mills, B. Clothier, M. van der Velde, R. Laplane, et al., "Phytoremediation: Using Plants as Biopumps to Improve Degraded Environments," Australian Journal of Soil Research, Vol. 41, No. 3, 2004, pp. 599-611. doi:10.1071/SR02131

[14] E. Lombi, "Phytoremediation of Heavy Metal-Contaminated Soils: Natural Hyperaccumulation versus Chemically Enhanced Phytoextraction," Journal of Environmental Quality, Vol. 30, 2001, pp. 1919-1926. doi:10.2134/jeq2001.1919

[15] B. E. Pivetz, "Phytoremeidation of Contaminated Soil and Ground Water at Hazardous Waste Sites," EPA GroundWater Issue, EPA/540/S-01/500, 2001, p. 36.

[16] K. Oh., M. Sugisaki, S. Hosono, F. Li and T. Hirano, "Study on Remediation of Dioxin-Contaminated Soil by PlantMicrobial Combinations," Organohalogen Compounds, Vol. 69, 2005, pp. 2536-2539.

[17] X. D. Huang, Y. El-Alawi, J. Gurska, B. R. Glick and B. M. Greenberg, "A Multi-Process Phytoremediation System for Decontamination of Persistent Total Petroleum
Hydrocarbons (TPHs) from Soils," Microchemical Journal, Vol. 81, No. 1, 2005, pp. 139-147. doi:10.1016/j.microc.2005.01.009

[18] E. M. Cooper and J. T. Sims, "Chelate-Assisted Phytoextraction of Lead from Contaminated Soils," Journal of Environmental Quality, Vol. 28, No. 6, 1999, pp. 17091719. doi:10.2134/jeq1999.00472425002800060004x

[19] EPA, "Introduction to Phytoremediation," Environmental Protection Agency, Washington, 2000.

[20] EPA, "Use of Field-Scale Phytotechnology for Chlorinated Solvents, Metals, Explosives and Propellants, and Pesticides," 2005.

[21] M. H. Wong, "Ecological Restoration of Mine Degradation Soils, with Emphasis on Metal Contaminated Soils," Chemosphere, Vol. 50, No. 6, 2003, pp. 775-780. doi:10.1016/S0045-6535(02)00232-1

[22] W. S. Shu, "Use of Vetiver and Other Three Grasses for Revegetation of $\mathrm{Pb} / \mathrm{Zn}$ Mine Tailings at Lechang, Guangdong Province: Field Experiment," 2nd International Vetiver Conference, Bangkok, 2002, pp. 56-63. 